\title{
Effectiveness of Resiliency Training on Quality of Life and Resiliency in Prisoners of War
}

\section{ART I C L E INF O}

\section{Article Type}

Original Research

\section{Authors}

Isanejad $0{ }^{* 1} \mathrm{PhD}$

Haydarian M. ${ }^{2} M A$

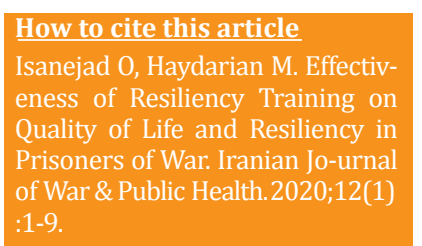

\section{A B S T R A C T}

Aims One of the important psychological dimensions of prisoners of war that in most societies can be threatened and often overlooked, is their quality of life, resilience and flexibility of these people. The aim of present study was to investigate the effectiveness of resiliency training on quality of life and resiliency in prisoners of war.

Materials \& Methods In this semi experimental study with pretest-posttest design with control group and fallow-up session (after 2 months) in 2017, 30 prisoners of war in Divandarreh city, Kurdistan province were selected by simple random sampling method and randomly assigned into experimental and control group (each group 15 people). The experimental group received resilience training for 10 sessions, but the control group did not receive any training. Data were gathered by Connor-Davidson Resilience Scale (CD-RISC) and the World Health Organization Quality of Life (WHOQOL-BREF) and analyzed using SPSS 18 software and multivariate analysis of covariance and one way analysis of covariance.

Findings At posttest and follow-up stages, the mean scores of resiliency and psychological, social and environmental domains of quality of life were significantly higher in the experimental group than the control group $(p=0.001)$, but there was no significant difference between the two groups in physical domain scores of quality of life $(p>0.05)$.

Conclusion Resiliency training can have a lasting and stable impact on improving the quality of life and resilience in prisoners of war.

Keywords Education; Prisoners of War; Resilience; Quality of Life

\section{I T A T I O N L I N K S}

[1] The implications of war captivity and ... [2] Where nothing happened: the experience ... [3] Later life disability status following ... [4] Positive adjustment among American ... [5] The prisoner of war ... [6] Universe, human immortality and future ... [7] Eating disorders and quality of life: a review ... [8] Quality of Life Therapy: Applying a life satisfaction approach ... [9] The encyclopedia of positive ... [10] Cohort differences in the marriagehealth relationship ... [11] Health-related quality of life--an ... [12] Lifestyle and healthrelated risk factors and risk ... [13] Eating disorder symptoms and comorbid ... [14] Developing a benefits counseling website for Veterans ... [15] Mental health and somatic symptom severity are ... [16] Evaluation of epidemiology of chronic disease in ... [17] Spirituality as a resiliency quality in Xhosa-speaking ... [18] Be happy: The role of resilience between ... [19] The impact of resilience among older ... [20] Understanding resilience. Front Behav ... [21] The metatheory of resilience and ... [22] The association of resilience and age in individuals ... [23] A systematic review of resilience in the ... [24] Relationship between resilience and quality ... [25] A review of medical experiences of Sepah in ... [26] Intrinsic religiosity, resilience, quality of life, and suicide ... [27] Effects of social support, hope and resilience on ... [28] Quality of life, vulnerability and resilience: A ... [29] Measuring the effectiveness of resilience ... [30] The efficacy of group awareness training of premenstrual ... [31] Improving mental health and quality of life through ... [32] Development of a resilience Fostering program ... [33] Psychological resilience in OEF-OIF Veterans: Application ... [34] Exploration of the resilience construct in ... [35] Development of a new resilience scale: the ... [36] Resilience and quality of mothers with mentally ... [37] The World Health Organization's WHOQOL ... [38] Development of the world Health organization ... [39] The World Health organization quality ... [40] Fostering family resiliency: a revirw ... [41] Resilience in aging ... [42] Psychological resilience and Intrinsic ... [43] Ordinary magic: resilience processes ... [44] Support for caring and resiliency among ... [45] Resiliency and religious orientation factors ... [46] Gender differences in aspects of psychological ... [47] A comparison of resiliency, marital satisfaction ...

\section{Article History}

Received: May 02, 2019

Accepted: November 13, 2019

ePublished: March 17, 2020 
همه بحرانها بهويزه جنگ اثرات طولانىمدتى را بر زندكى اجتماعى

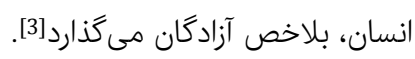

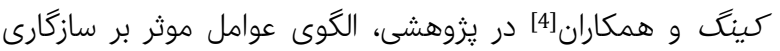

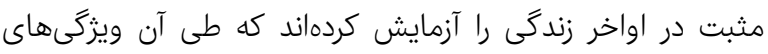

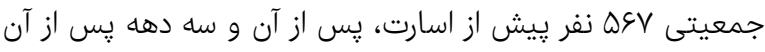

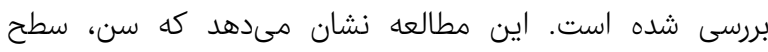
تحصيلات و شكنجههاى جسمى در زمان اسارت با تريشانى إنهاى

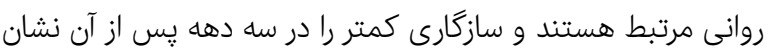

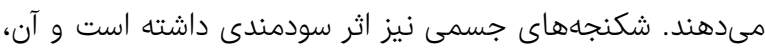

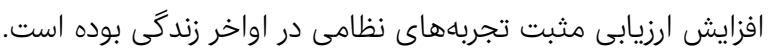

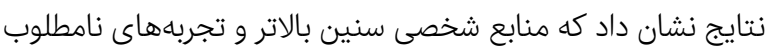

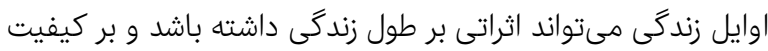

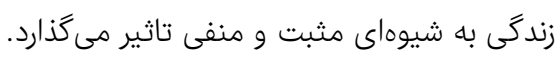

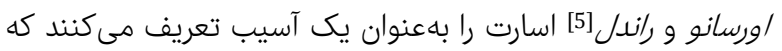

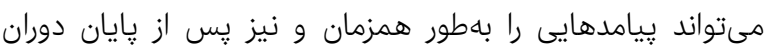

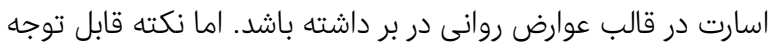

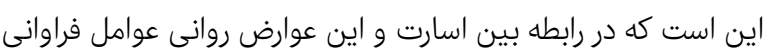

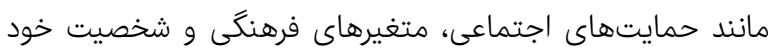
افراد نيز نقش ايفا مىكنند و تجربههاى متفاوتى از اسارت منات را براى

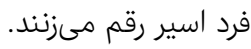
از جمله ابعاد مهم روانشناختى افراد آزاده و جانباز كه در اغلب

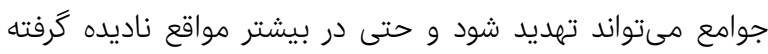

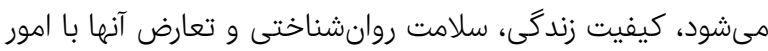

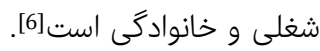

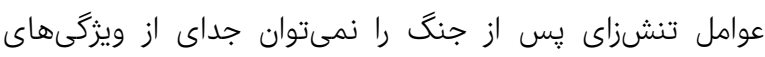

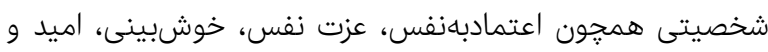

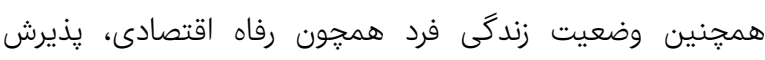

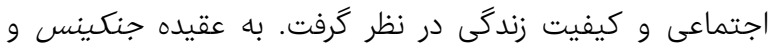

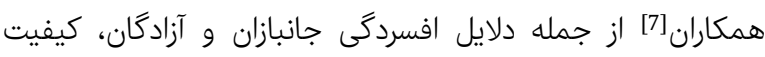

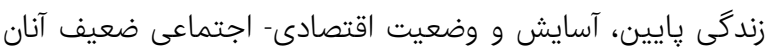

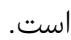

كيفيت زندگى يكى از بنيادىترين مفاهيمى است كه همسو با

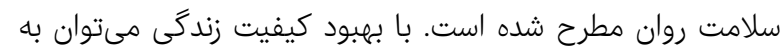

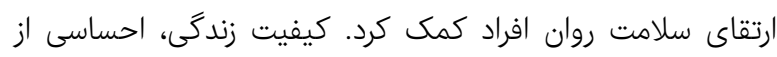

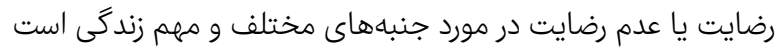

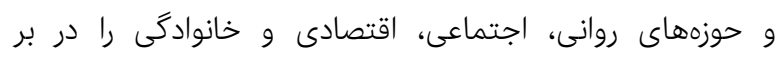

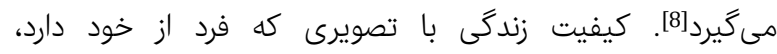

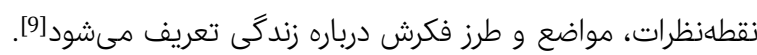

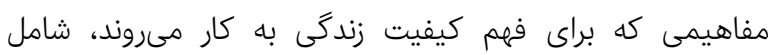

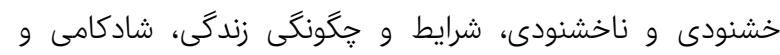

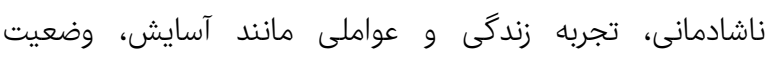

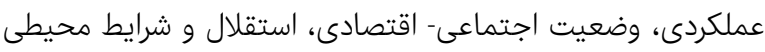

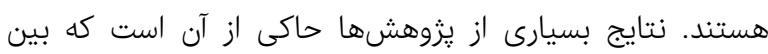

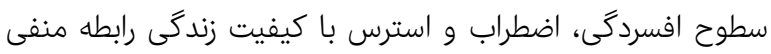

\section{اثربخشى آموزش تابآورى بر بهبود كيفيت زندگى} و تابآورى آزادگان

PhD * اميد عيسىنزاد

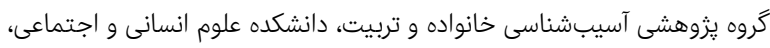

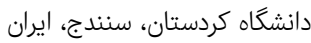

MA منصور حيدريان كروه مشاوره، دانشكده علوم انسانى و اجتماعى، دانشكاه كردستان، سنداج، ايران

جكيده اهداف: از جمله ابعاد مهم روانشناختى آزادكان كه در اغلب جوامع مىتواند

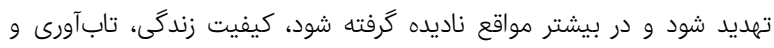

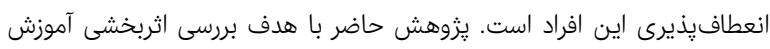

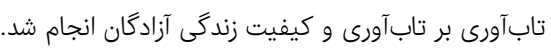

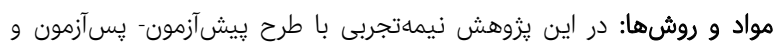

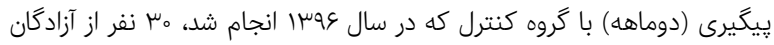

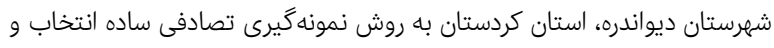

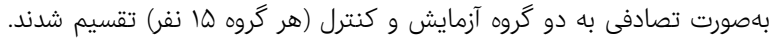

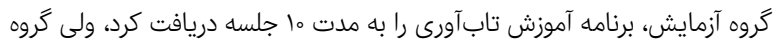

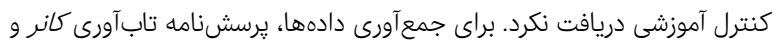

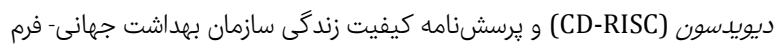

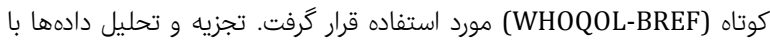

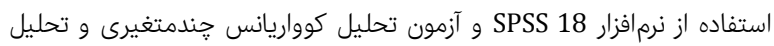
كوواريانس يكراهه انجام شد.

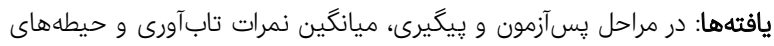

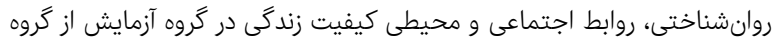

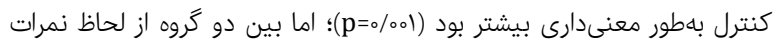

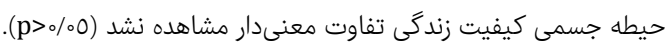

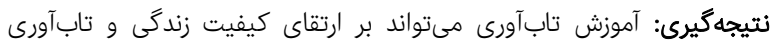

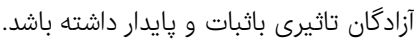

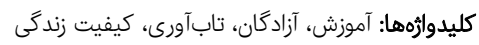

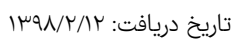

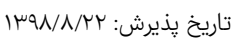

نويسنده مسئول:

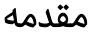

اسارت در دورههاى مختلف تاريخى و همزمان با بسيارى از جنگَها

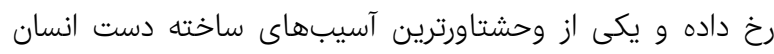

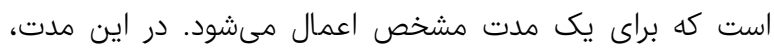

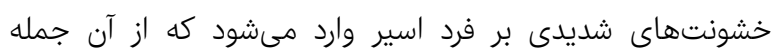

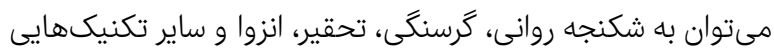

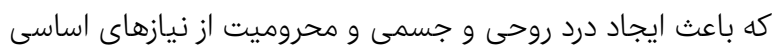

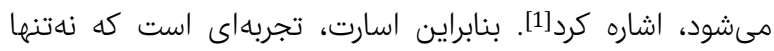

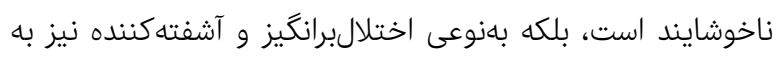
شمار مىرود[2]. اسارت اثرات ماندكارى در جسم و و روان اندان اسيران،

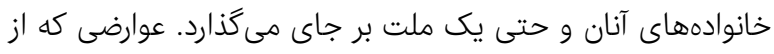
دوران اسارت به جا مانده است، اثرات اين دوران ران ران ماندكارتر مى كندان. 


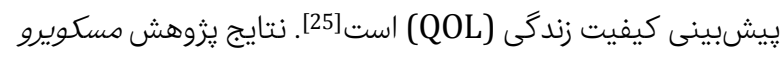

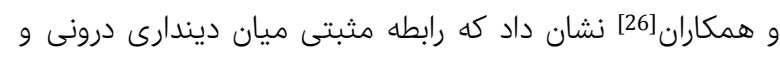

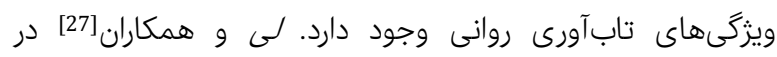

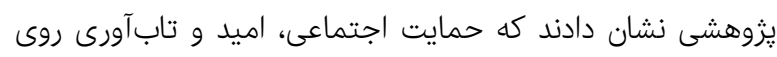

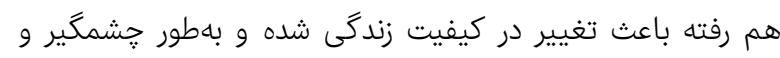

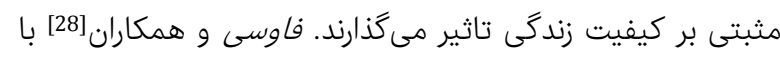

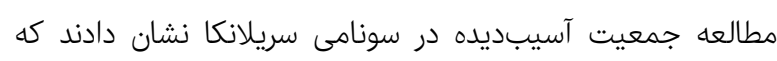

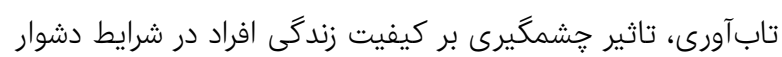

نتايج يزوهش آيدلخانى و حيدرى [29] نشان داد كه برنامه آموزش

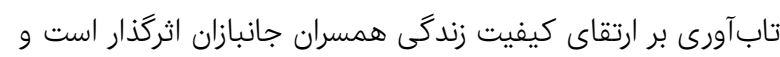

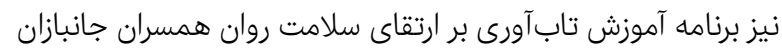

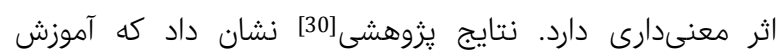

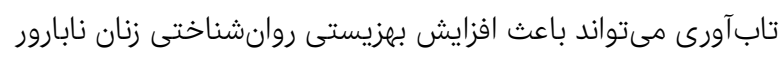

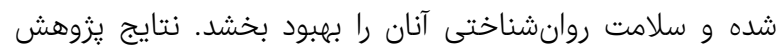

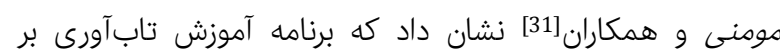

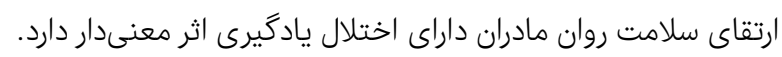

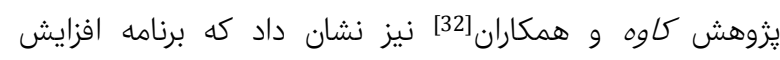

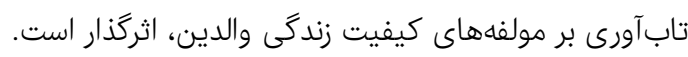

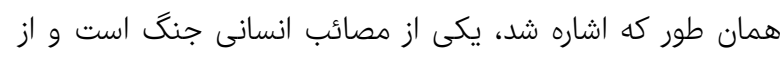

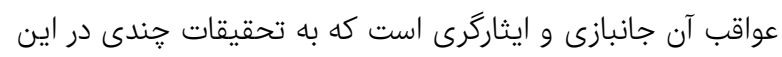

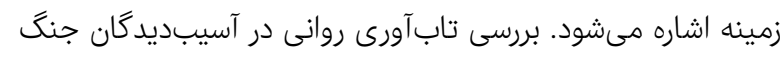

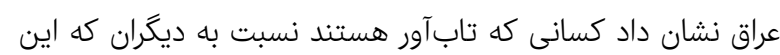

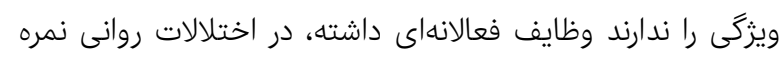

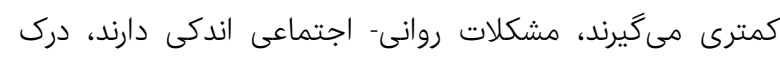

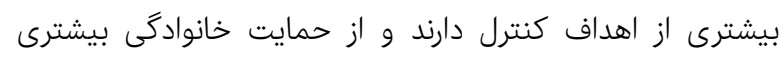

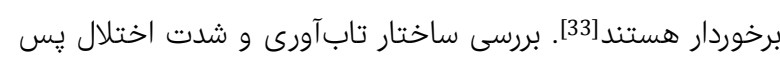

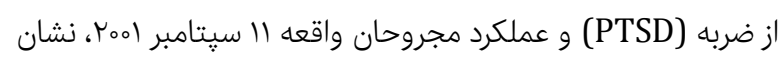

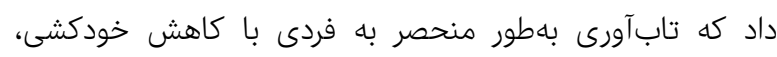

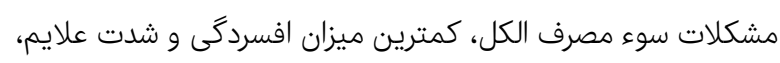

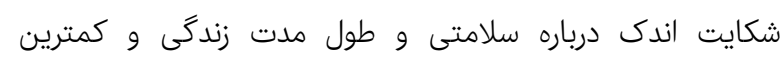

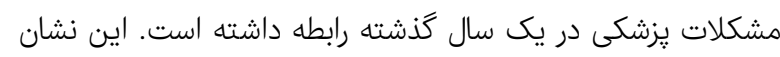

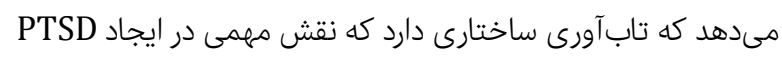

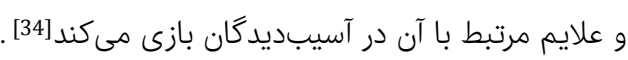

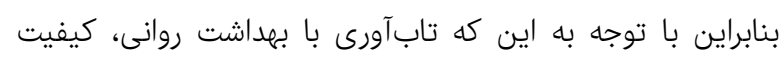

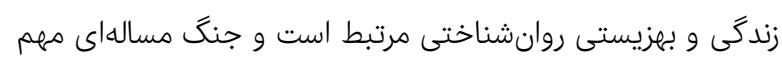

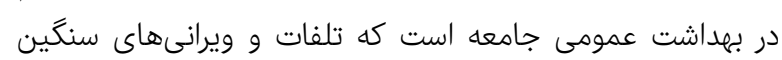

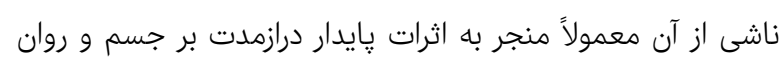

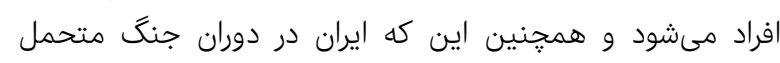

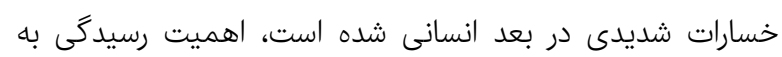

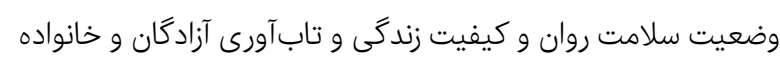

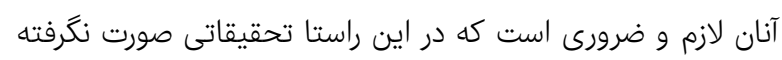

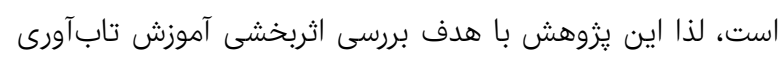

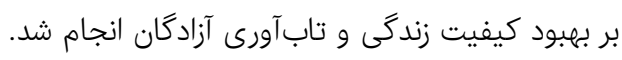

وجود دارد و برعكس سطوح بالاى كيفيت زندگى و اميد با

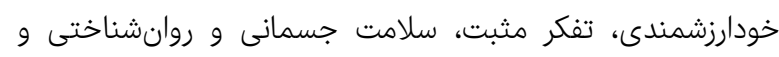

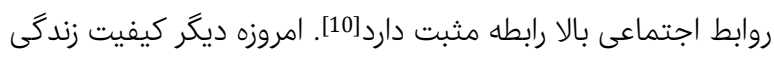

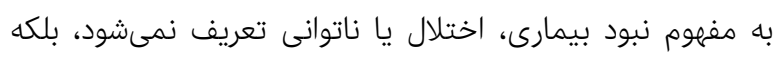

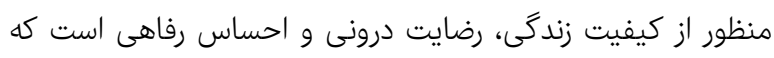

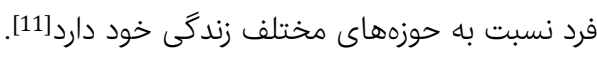

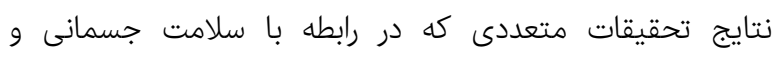

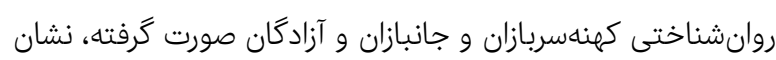

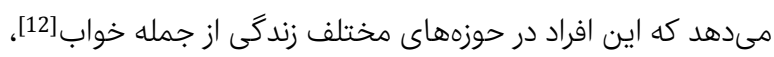

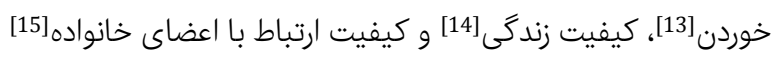
داراى مشكلات عديده و قابل توجهى هستند.

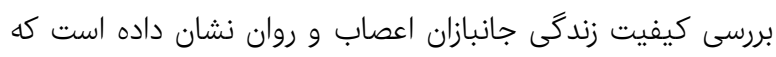

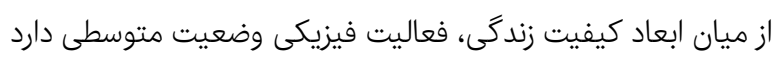

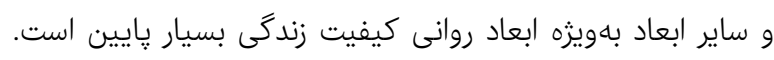

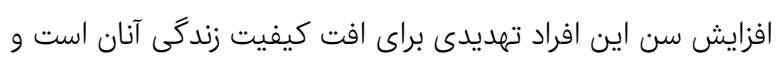

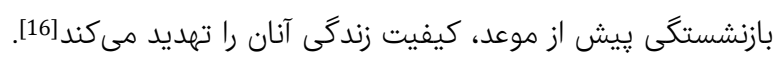

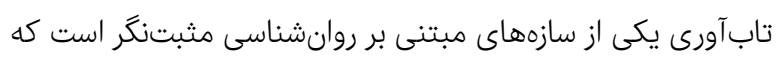

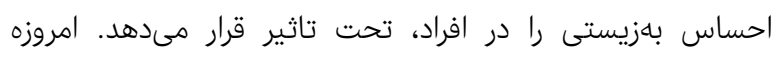

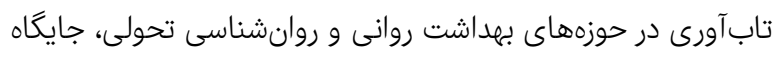

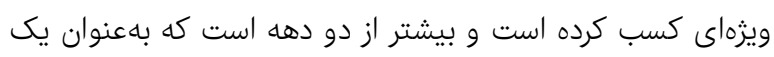

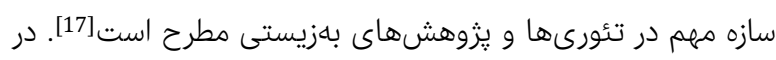

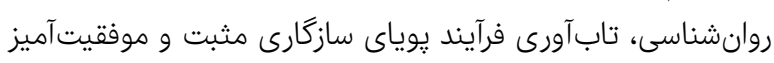

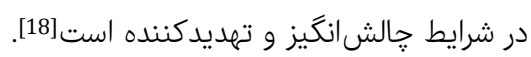

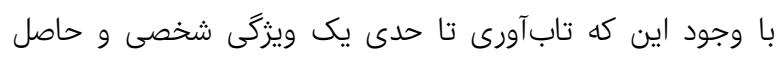

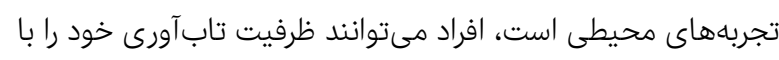

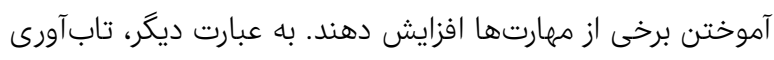

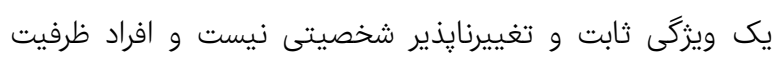
بازسازى و تابآوردن را دارند [19.

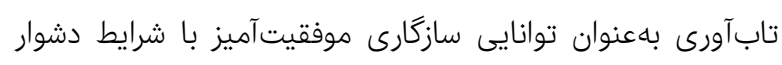

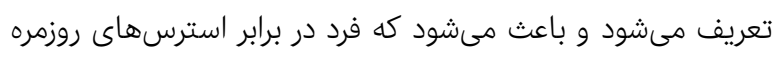

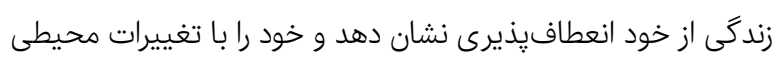

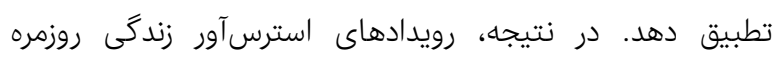

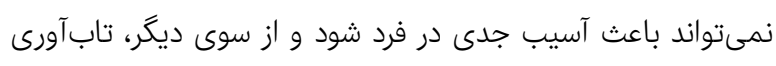

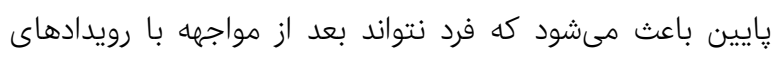

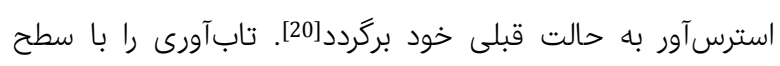

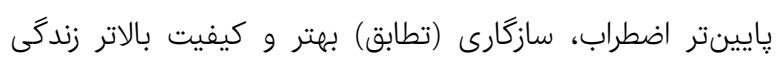

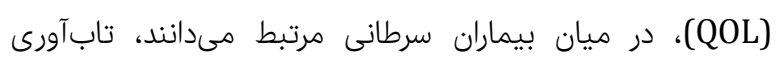

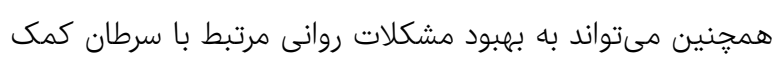
كند [21, 22]. بررسى يزوهشها نشان مىدهد كه تابآورى روانشناختى باعث

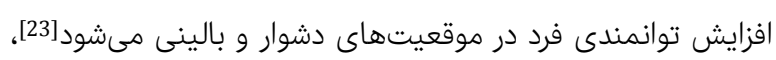

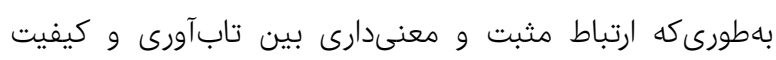

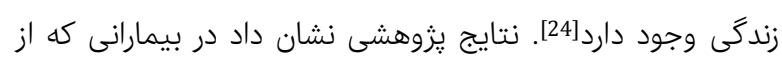

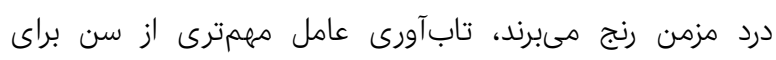




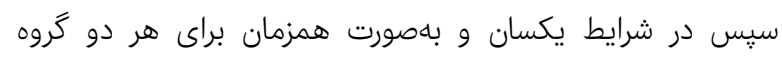

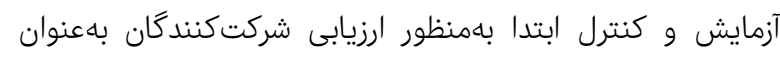

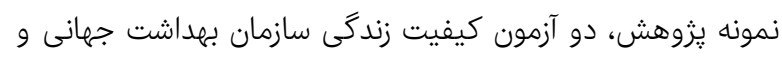

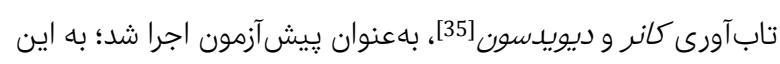

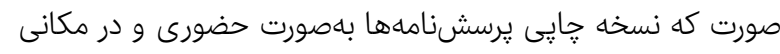

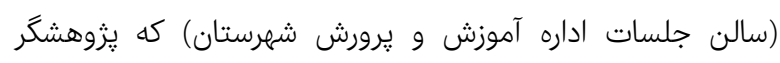

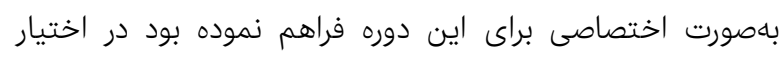

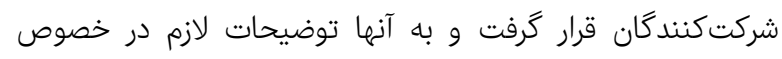

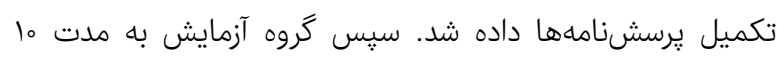

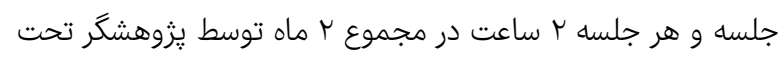

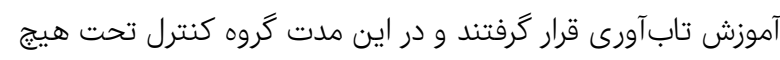

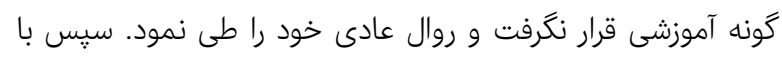

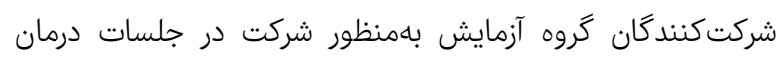

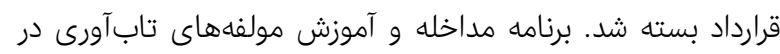

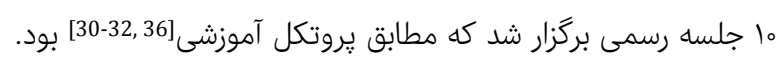

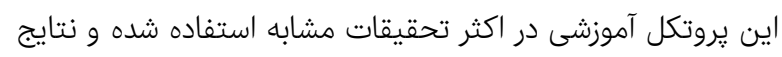

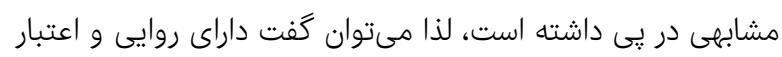

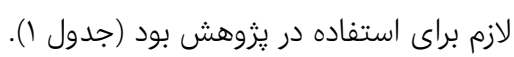

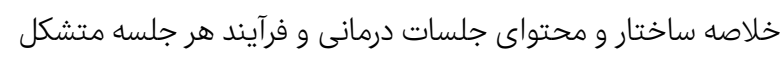

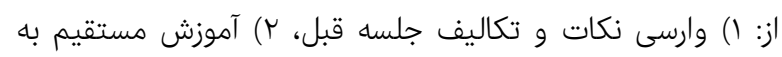

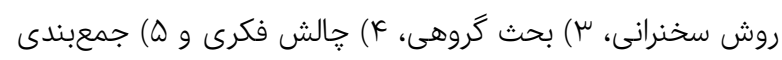

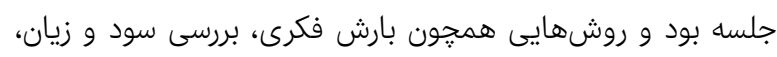

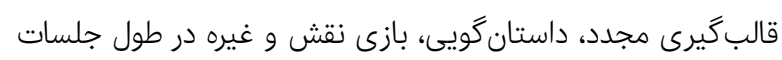

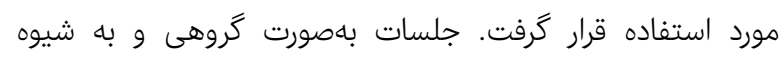

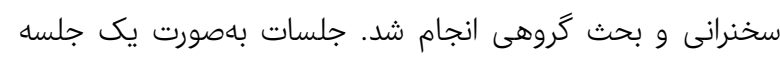

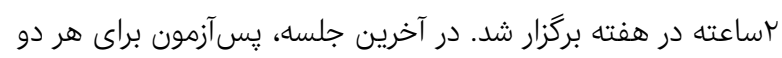

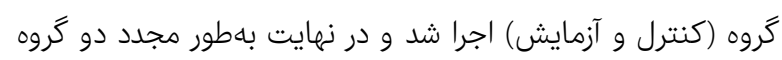

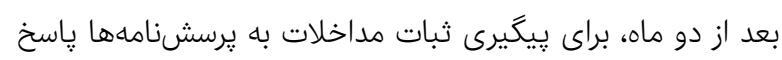

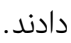

بهمنظور رعايت ملاحظات اخلاقى، ابتدا رضايت شركت كنندكان براى

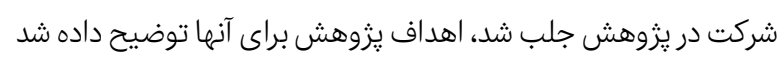

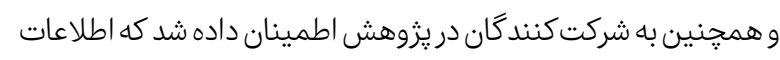

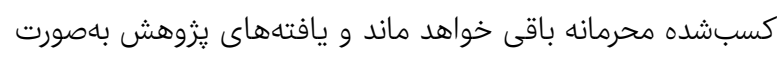

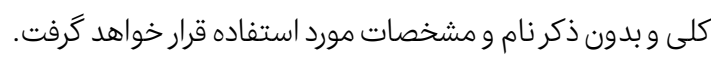

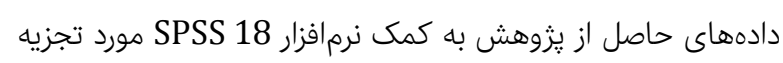

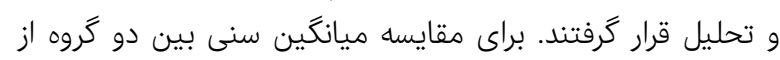

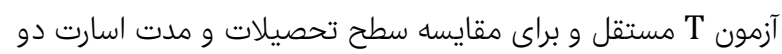

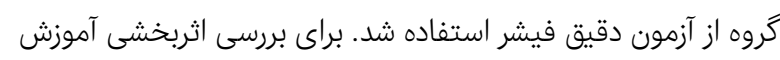

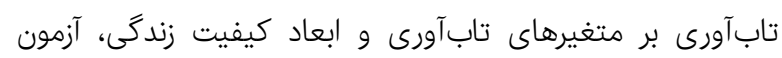

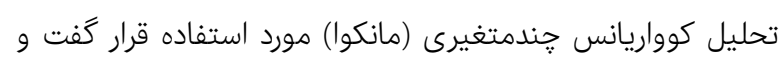

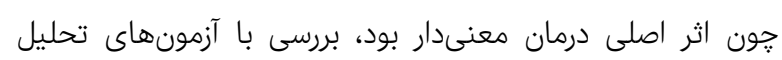

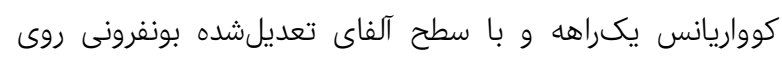
نمرات تابآورى و ابعاد كيفيت زندكى ادامه يافت.
مواد و روشها

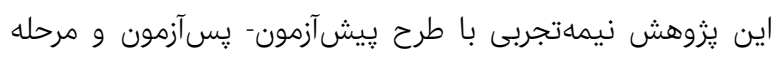

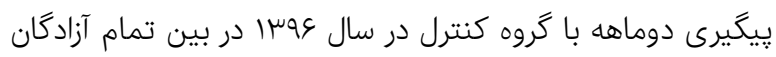

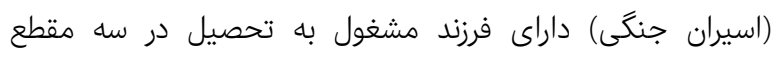

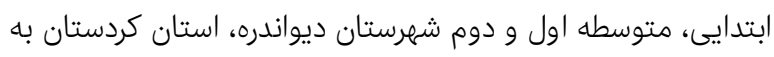

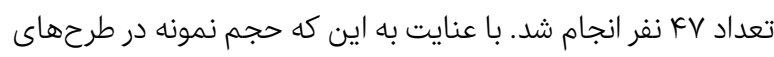

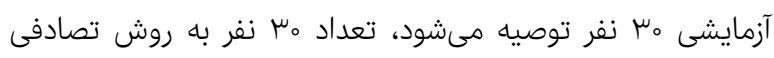

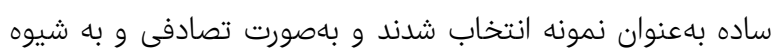

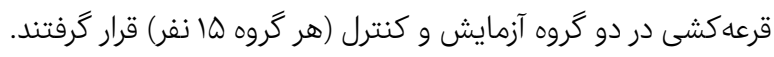

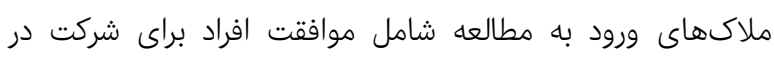

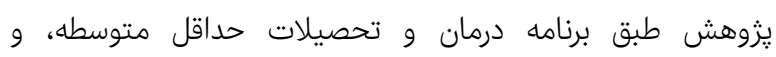

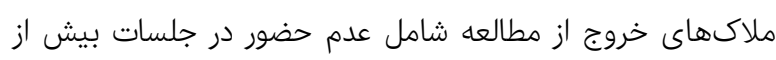

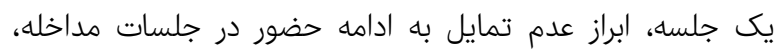

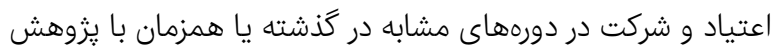

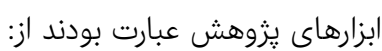

ا- برسشنامه تابآورى كانر و ديونيدسون (CD-RISC): اين

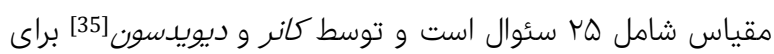

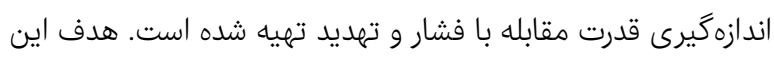

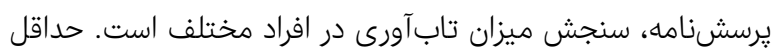

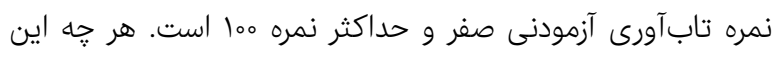

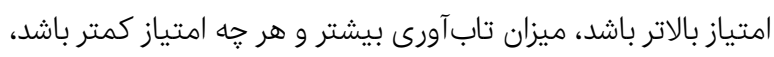

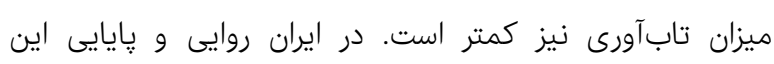

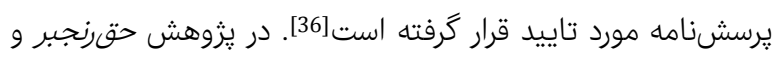

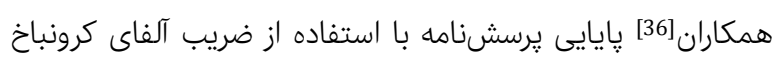

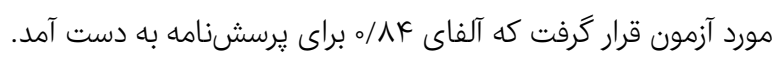

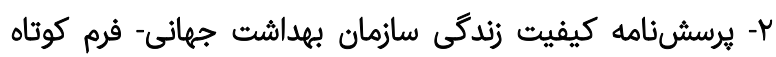
(WHOQOL-BREF)

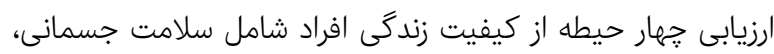

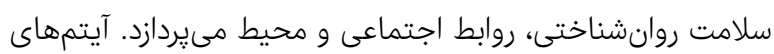

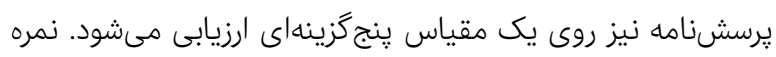

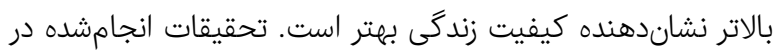

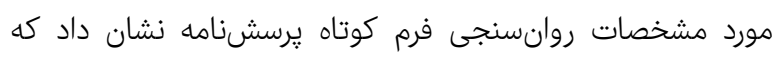

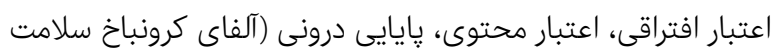

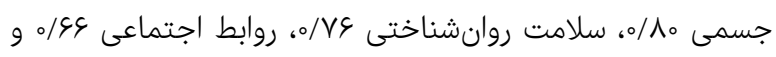

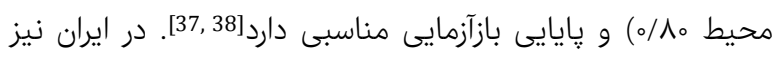

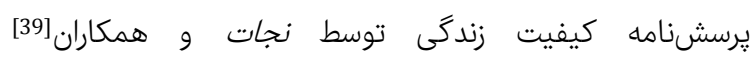

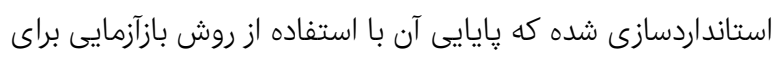

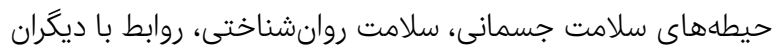

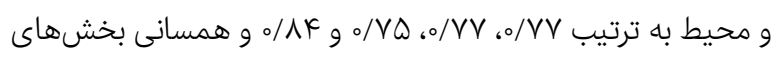
مختلف آن با استفاده از روش آلفاى كرونباخ براى افراد سالم و بيماره

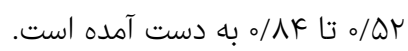
در آغاز مطالعه، سن، تحصيلات داء و مدت است اسارت همه افراد ثبت شد. 


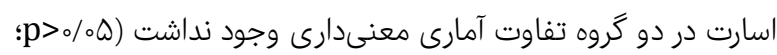

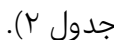

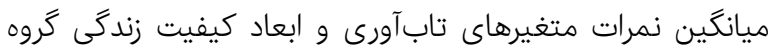

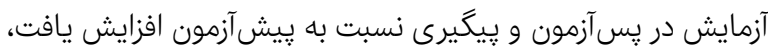

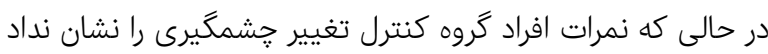

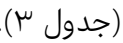

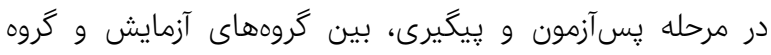

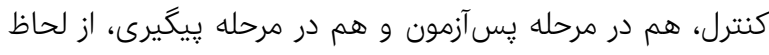

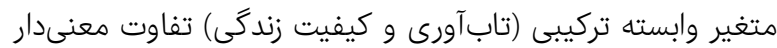

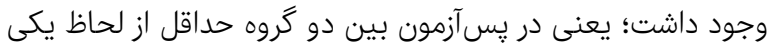

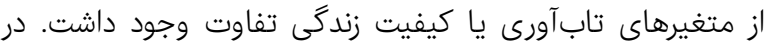

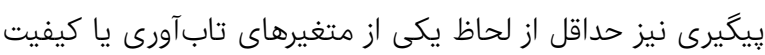

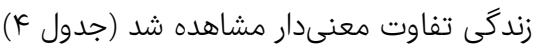

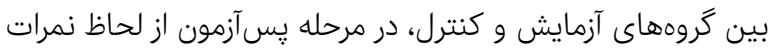

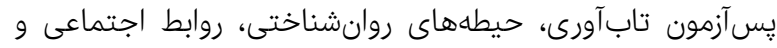

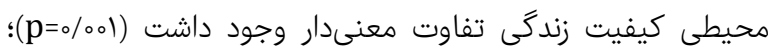

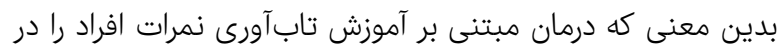

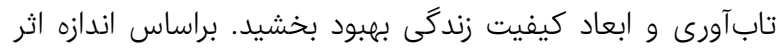

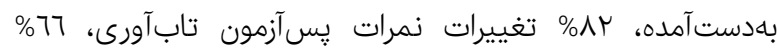

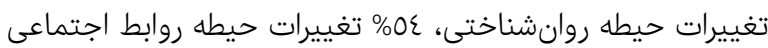

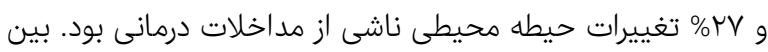

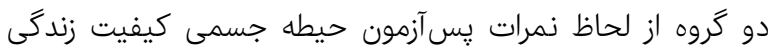

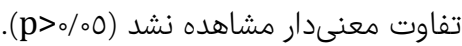

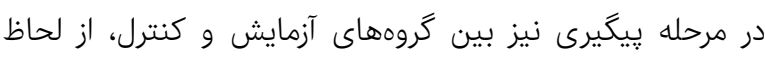

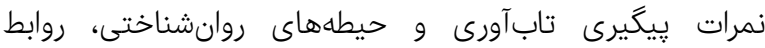

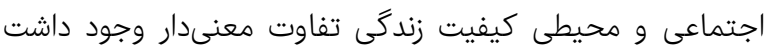

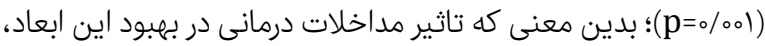

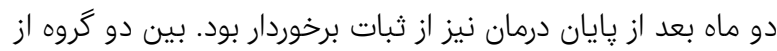

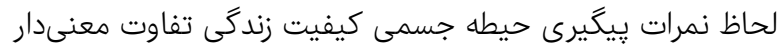

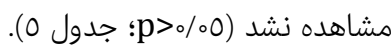

جلسه اول

آشنايى اعضا با هم و اجراى ييشآزآمون، معارفه با اعضاى گروه، آشنايى با برنامه و هدف، آشنايى اعضا با مفهوم تابآورى آناي جلسه دوم آكاهى نسبت به توانمندىهاى خود: ارايه تعريف از خودآكاهى و مولفههاى

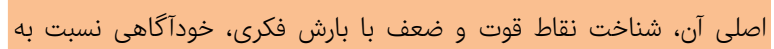

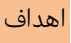
جلسه سوم تقويت عزت نفس: ارايه درى روشنى از عزت نفس، شناسايى ضعفهاى خود و تلاش براى برطرفكردن آنها

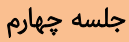
ارتقاى توانايى افراد در برقرارى ارتباط: بيان تعريف ساده از ارتباط، بيان

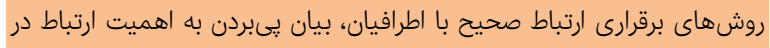

جلسه هنجم

برقرارى روابط اجتماعى، نقش حمايت اجتماعى در شرايط دشوار، تشخيص

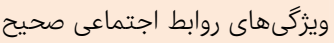

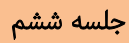

تعيين هدف، تمييزدادن اهداف كوتاهمدت و بلندمدت، تعيين خند هدف كوتاه

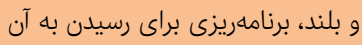
جلسه هفتم خودكارآمدى و تاثير آن در زندگى، بيان مفهوم تصميمگيرى و معيارهاى يك خيك

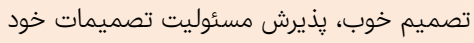

جلسه هشتم خودكارآمدى از طريق حل مساله، آشنايى و مراحل آن، تفكر در مورد مشكلات آنات

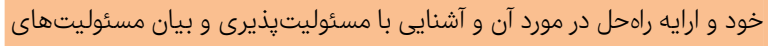

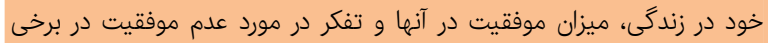
مسئوليتها و ارايه راهكار ميزان موقيت

جلسه نهم

مديريت خشم، استرس و اضطراب و نشانههاى آن، ارايه جند راهبرد رفتارى براى

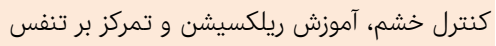

جلسه دهم

يرورش حس معنويت و ايمان: بحث در مورد نقش معنويت در زندگى، ارايه

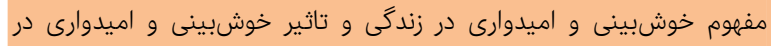

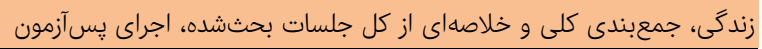

يافتهها

ميانكين سنى در گروه كنترل

جدول r) مقايسه توزيع فراوانى مطلق و نسبى ويثگىهاى جمعيتشناختى در دو گروه آزمايش و كنترل (هر گروه Qا نفر؛ اعداد داخل برانتز، درصد هستند)

\begin{tabular}{|c|c|c|c|}
\hline سطح معنىدارى & كروه كنترل & كروه آزمايش & متغيرها \\
\hline \multirow{4}{*}{$1 / \%$} & & & سطح تحصيلات \\
\hline & $\varepsilon\left(K_{0} / 0\right)$ & $\varphi\left(K_{\%} / 0\right)$ & زير دييلم \\
\hline & $\wedge(\Delta \mu / \mu)$ & $\wedge(\Delta \mu / \mu)$ & دييلم \\
\hline & $1(\varepsilon / V)$ & $I(\varepsilon / V)$ & فوق دييلم و بالاتر \\
\hline \multirow{5}{*}{$\circ / Y \Lambda$} & & & مدت اسارت \\
\hline & $\circ$ & $I(\varepsilon / V)$ & كمتر از 8 ماه \\
\hline & $\mu\left(r_{0} / \circ\right)$ & $1(\varepsilon / V)$ & ع ماه تا يك سال \\
\hline & $r(1 \mu / \mu)$ & $\Delta(\mu \mu / \mu)$ & يك تا r سال \\
\hline & $10(94 / V)$ & $\wedge(\Delta \mu / \mu)$ & r سال و بيشتر \\
\hline
\end{tabular}


ع اميد عيسىنزاد و منصور حيدريان

\begin{tabular}{|c|c|c|c|}
\hline \multicolumn{4}{|c|}{ جدول س) ميانكين آمارى متغيرهاى تابآورى و حيطههاى كيفيت زندگى در گروههاى آزمايش و كنترل در مراحل مختلف يزوهش } \\
\hline بيگيرى & يسآزمون & بيش آزمون & إلغيرها \\
\hline & & & تابآورى \\
\hline$\Lambda_{0} / \Lambda_{0} \pm \varepsilon / \mu \mu$ & $\Lambda \mu / \circ \pm \pm \varepsilon / \kappa q$ & $V 0 / \circ \circ \pm 10 / \mu r$ & كروه آزمايش \\
\hline$V Y / \Lambda \circ \pm I r / I K$ & $V \mu / r \varepsilon \pm 1 Q / \circ V$ & $V K / \varepsilon_{0} \pm 1 Q / \mu K$ & كروه كنترل \\
\hline \multicolumn{4}{|c|}{ حيطه جسمى كيفيت زندگى } \\
\hline$r \mu / \Lambda \circ \pm l / \Lambda q$ & $r K / \varepsilon_{0 \pm} \pm / \circ \varphi$ & $r r / \Lambda \circ \pm F / \circ q$ & كروه آزمايش \\
\hline$r \mu / v \mu_{ \pm}+r / Q \Lambda$ & $r \mu / \kappa \varepsilon_{ \pm} \mu / \Delta_{0}$ & $\mu K / \circ \pm \Psi \% V$ & كروه كنترل \\
\hline \multicolumn{4}{|c|}{ حيطه روانشناختى كيفيت زندگى } \\
\hline$r r / \circ \pm I / \wedge \Delta$ & $r r / \Lambda \circ \pm r / \circ \circ$ & $19 / \Lambda \varepsilon \pm r / V q$ & كروه آزمايش \\
\hline $19 / \% \varphi_{ \pm} \mu / \& V$ & $r_{0} / \varphi_{ \pm} \pm / \mu \varepsilon$ & $r_{0} / \varepsilon_{0} \pm k / r_{0}$ & كروه كنترل \\
\hline \multicolumn{4}{|c|}{ حيطه روابط اجتماعى كيفيت زندگى } \\
\hline $\mid 1 / 99 \pm 1 / 9 V$ & $|r /| \mu_{ \pm} \mid / q k$ & $10 / 99 \pm 1 / 9 \Lambda$ & كروه آزمايش \\
\hline $10 / 9 \circ \pm r / 98$ & $\| / \wedge \varepsilon \pm r / \omega_{0}$ & $\| / N \mu \pm r / \Delta \mu$ & كروه كنترل \\
\hline \multicolumn{4}{|c|}{ حيطه محيطى كيفيت زندگى } \\
\hline$\mu r / \circ \pm \Psi / \omega_{0}$ & $\mu \tau / \mathcal{K}_{0} \pm \mu / \mathcal{K}_{0}$ & $r V / \Delta \Psi \pm F / K Q$ & كروه آزمايش \\
\hline$r \varepsilon / \mu \mu \pm \Delta / 1$ 。 & $r V / V \mu_{ \pm}+\Lambda / I r$ & $r \varepsilon / K \circ \pm \Delta / \kappa r$ & كروه كنترل \\
\hline
\end{tabular}

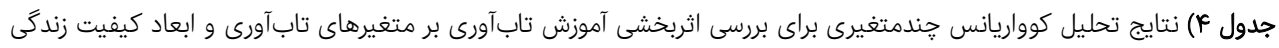

\begin{tabular}{|c|c|c|c|c|c|}
\hline توان آمارى & اندازه اثر & سطح معنىدارى & Fقدار F F F F & ارزش & مراحل يُروهش \\
\hline & & & & & مرحله يسآزمون \\
\hline 1 & $\circ / Q_{\circ} \mu$ & $\circ / 001$ & $\mu \omega / \mu \mu$ & $\circ / 9 . \mu$ & اثر پِيلايى \\
\hline 1 & $\circ / q_{\circ} \mu$ & $\% 001$ & $\mu \omega / \mu \mu$ &.$\% 9 V$ & لامبداى ويلكز \\
\hline & & & & & مرحله بِيخيرى \\
\hline 1 &.$/ 91$ & $\circ / 001$ & $\mu / / \Lambda$ &.$/ 91$ & اثر پييلايى \\
\hline 1 &.$/ 91$ & $\%$ & $\mu^{\prime} / / \Lambda$ & $\% 1 \wedge$ & لامبداى ويلكز \\
\hline
\end{tabular}

جدول 0) نتايج تحليل كوواريانس يكراهه نمرههاى بِآزمون و بِيگيرى در گروههاى آزمايش و كنترل

\begin{tabular}{|c|c|c|c|c|c|c|}
\hline توان آمارى & اندازه اثر & سطح معنىدارى & Fقدار F F F & مجموع مجذورات & منبع تغييرات & ا متغيرها \\
\hline 1 & o/Ar & $\% \circ 01$ & $10 N / \Lambda$ & $\begin{array}{l}110 V / \mu q \\
r \mu w / q F\end{array}$ & خروها & 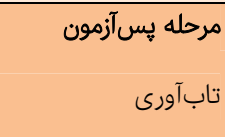 \\
\hline$\circ / V k$ & $\circ / M K$ &.$/ 14$ & $V / \mu V$ & $\begin{array}{l}\mathrm{M} / \Lambda \\
\text { G/० }\end{array}$ & خروه & حيطه جسمى \\
\hline 1 & $0 / 99$ & $\%$ & $k \Delta / . q$ & $\begin{array}{l}\omega_{0} / \& \mu \\
r \Delta / A r\end{array}$ & خروه & حيطه روانشناختى \\
\hline 1 & o/DF & $\%$ & rN/Or & $\begin{array}{l}\mid \varepsilon / \Delta F \\
\mid r / \Delta V\end{array}$ & خروها & حيطه روابط اجتماعى \\
\hline ०/入 & $0 / T Y$ & $\% \circ \mathrm{V}$ & N/VK & $\begin{array}{l}100 / \circ \Lambda \\
r V E / Y G\end{array}$ & خروها & حيطه محيطى \\
\hline 1 & $\circ / \wedge 1$ & $\% 001$ & $101 / \mu$ & $\begin{array}{l}Q Y \mu / q \\
r \mu l\end{array}$ & خروها & ترحله پيخيرى \\
\hline$\circ / Q$ & $\circ / 1 Q$ & $\% \Delta \Delta F$ & $k / 1$ & $\begin{array}{l}\varepsilon / \mu r \\
\mu \Delta / \mu\end{array}$ & خروها & حيطه جسمى \\
\hline 1 & o/DK & $\%$ & $r \varepsilon / 9$ & $\begin{array}{l}\Delta \Lambda / q \\
\omega_{0} / r\end{array}$ & خروه & حيطه روانشناختى \\
\hline 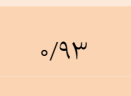 & G & $\% 001$ & 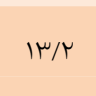 & $\begin{array}{l}1 r \\
r o / 9\end{array}$ & خروه & حيطه روابط اجتماعى \\
\hline 1 & $\circ / V$ & $\%$ & $\Delta \mu / \varsigma$ & $\begin{array}{l}191 \\
9 N / 9\end{array}$ & خروه & حيطه محيطى \\
\hline
\end{tabular}




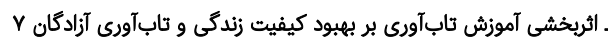

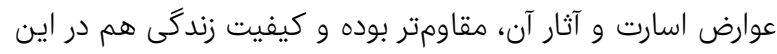

وضعيت بالاتر خواهد بود.

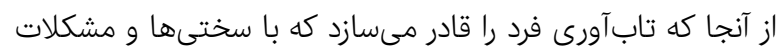

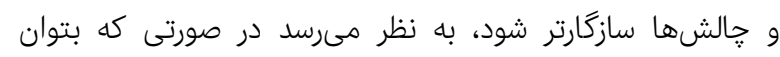

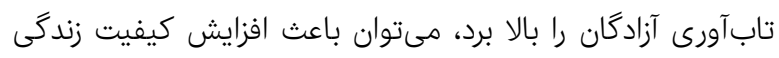

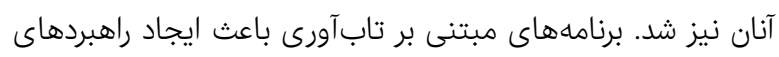

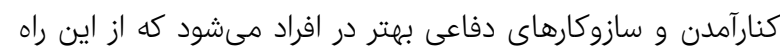

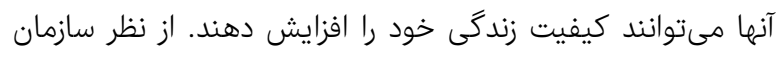

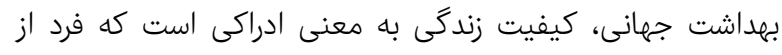
وضعيت خود با توجه به نظام فرهنكى و ارزشى، اهداف و معيارها شامل نكرش فرد به سلامت جسمى، وضعيت روانى، سطح استقلال،

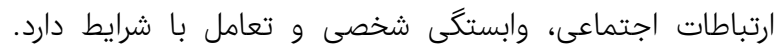
ويزگگىهاى روانشناختى كه بهعنوان خصوصيات موثر افراد جامعها

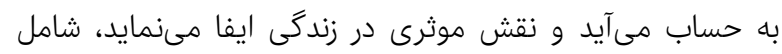

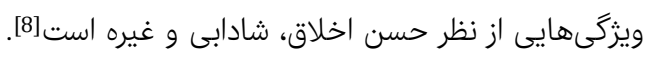

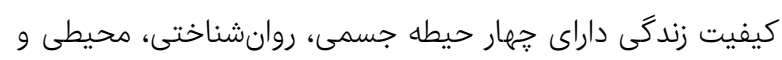

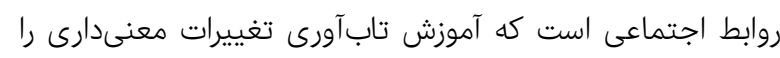

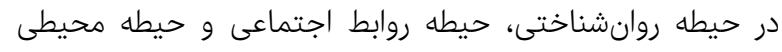

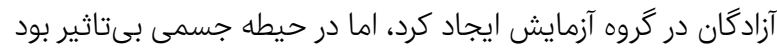

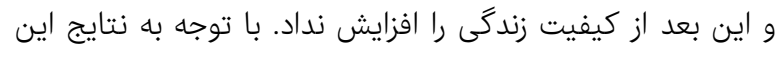

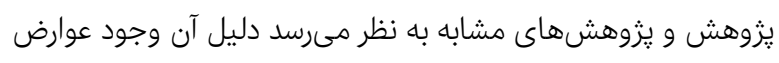

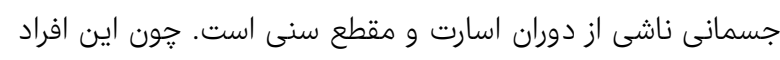

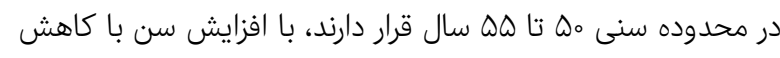

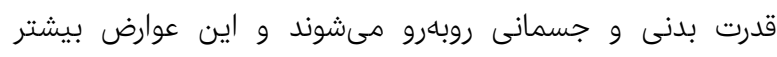

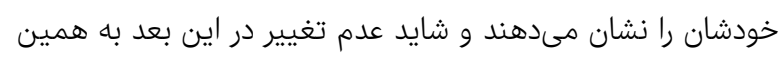

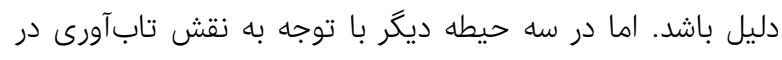

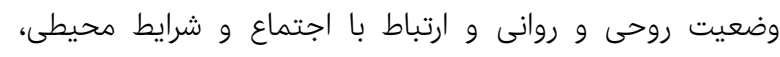
جلسات درمان تاثيرگذار بوده است كه در برنامه آموزش به إنه اين موارد

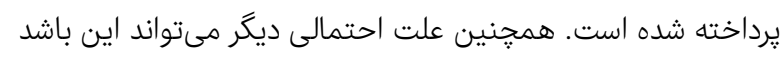

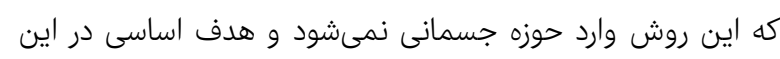
حيطه ندارد، بنابراين آموزش و مداخلهاى نيز درو جسمانى زمينه ودينه جسمى ارايه

نمى كند.

آموزش تابآورى مطابق يروتكل آموزشى باعث افزايش

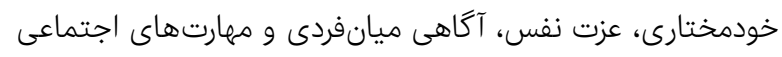

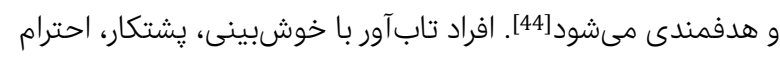

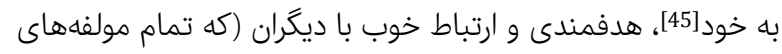

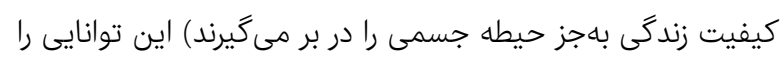

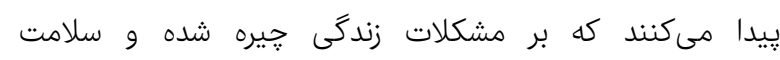

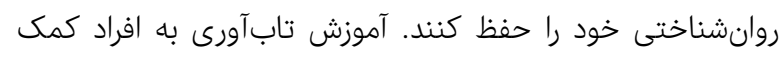

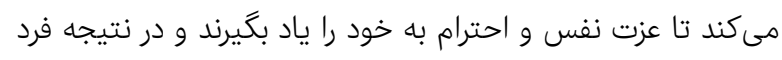

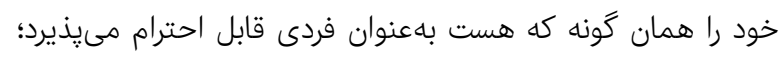

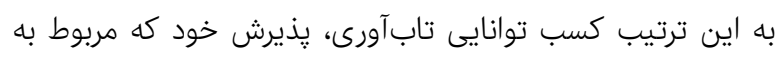

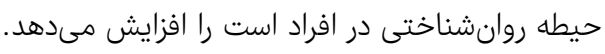

بحث

يزوهش حاضر با هدف بررسى اثربخشى آموزش تابآورى بر بهبود

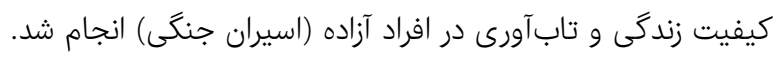

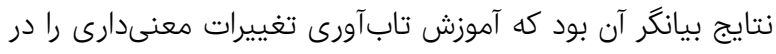

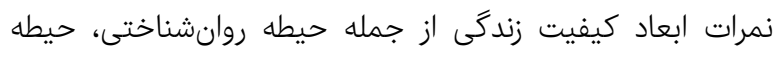
روابط اجتماعى و حيطه محيطى آزادگان گروه آزمايش در مران مرحله

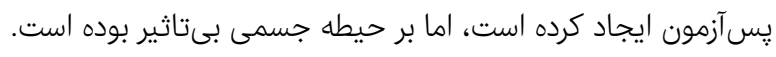
بررسى يزوهشها نشان داد كه يزوهشى با عنوان عيناً مشابه مطالعه آزها

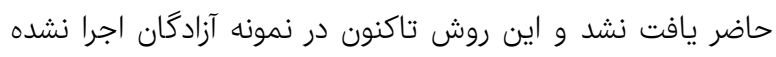

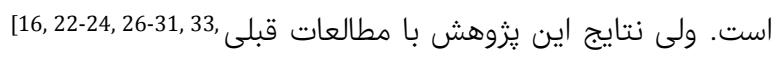

[34 در مورد اثربخشى تابآورى بر كيفيت زندگى همسو است.

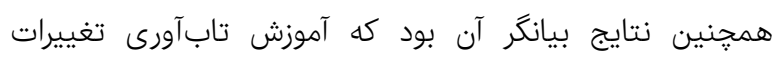
معنىدارى را در نمرات تابآورى آزادگًان گَروه آزمايش در در مرحله

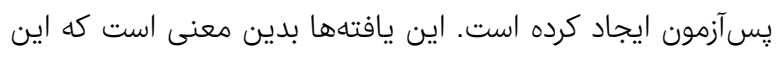

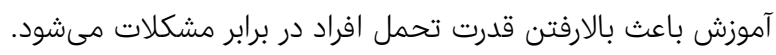

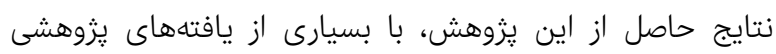

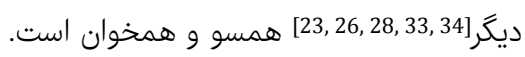

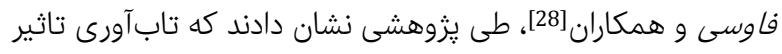

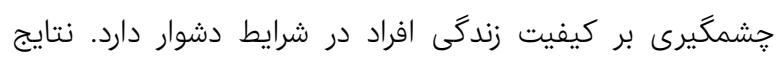

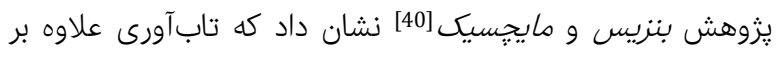

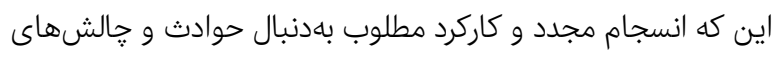

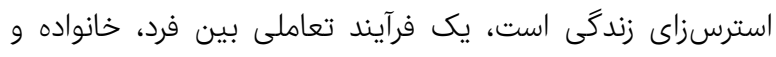

اجتماع است.

به لحاظ نظرى مىتوان گَفت تابآورى، بيانكر توانايى فرد براى

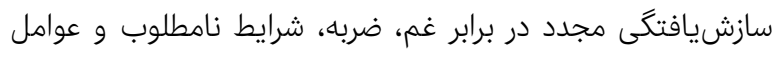

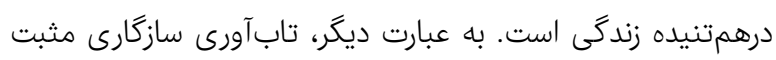

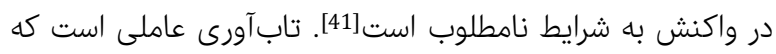

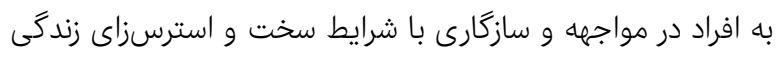

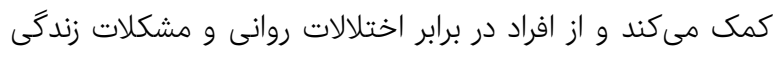

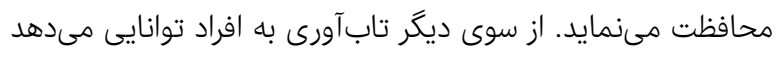

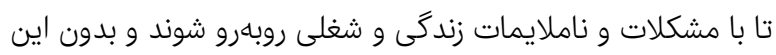

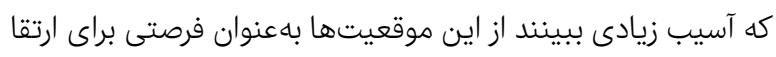

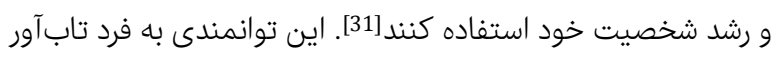
كمك مىكند كه شرايط استرسزا را مديريت كند و در مقابله

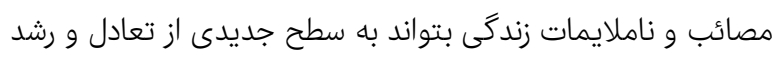

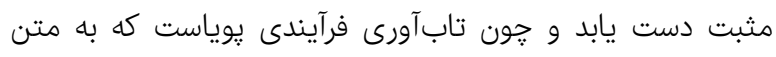

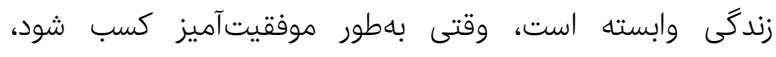
قابليتهاى فردى را تقويت مىكند. بهطور كلى تابآورى به به مفهوم ييامدهاى مثبت بهرغم تجربههاى ناگوار و ناملايمات، عملكرد

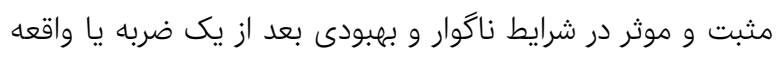

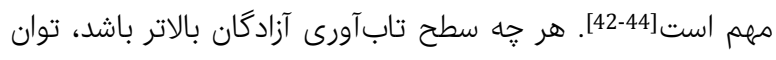
عملكرد مثبت در شرايط ناگوار بالا مىرود و مى هنوالوانند در برابر

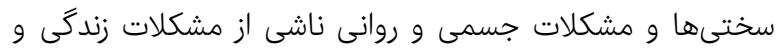


تابآورى آزادگًان تاثيرى باثبات و پِايدار داشته باشد.

تشكر و قدردانى: از مسئولان محترم بنياد شهيد و امور ايثاركران شهرستان

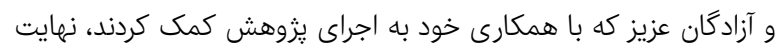
تشكر و سياسكزارى به عمل مى آيد آيد.

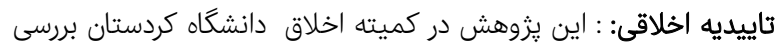

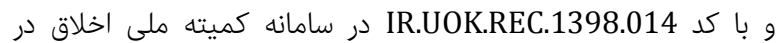
يثروهش ثبت شده است. تعارض منافع: تعارض منافعى وجود ندارد.

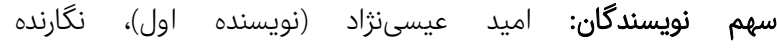

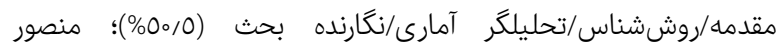

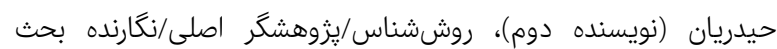
(\%乞१/0) منابع مالى: اين يُزوهش با حمايت مالى دانشگًاه كردستان انجام شده

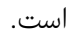

منابع

1- Solomon Z, Tsur N, Levin Y, Uziel O, Lahav M, Ohry A. The implications of war captivity and long-term psychopathology trajectories for telomere length. Psychoneuroendocrinology. 2017;81:122-8.

2- Jacques J. Where nothing happened: the experience of war captivity and levinas's concept of the 'there is'. Soc Legal Stud. 2017;26(2):230-4.

3- Hunt SC, Orsborn M, Checkoway H, Biggs ML, McFall M, Takaro TK. Later life disability status following incarceration as a prisoner of war. Mil Med. 2008;173(7):613-8.

4- King DW, King LA, Park CL, Lee LO, Kaiser AP, Spiro A, et al. Positive adjustment among American repatriated prisoners of the Vietnam War: Modeling the long-term effects of captivity. Clin Psychol Sci. 2015;3(6):861-76.

5- Ursano RJ, Rundell JR. The prisoner of war. In: Jones FD, Sparacino LR, Wilcox VL, Rothberg JM, Stokes JW, editors. War psychiatry. Falls Church, Virginia: Office of the Surgeon General Army; 1995. p. 431-55.

6- Bolonkin A. Universe, human immortality and future human evaluation. 1' Edition. Waltam, USA: Elsevier; 2011.

7- Jenkins PE, Hoste RR, Meyer C, Blissett JM. Eating disorders and quality of life: a review of the literature. Clin Psychol Rev. 2011;31(1):113-21.

8- Frisch MB. Quality of Life Therapy: Applying a life satisfaction approach to positive psychology and cognitive therapy. Hoboken, NJ: John Wiley \& Sons Inc; 2006.

9- Lopez SJ. The encyclopedia of positive psychology. Chichester, U.K: Wiley Black well publishing Ltd; 2009. p. 1160.

10- Newton NJ, Ryan LH, King RT, Smith J. Cohort differences in the marriage-health relationship for midlife women. Soc Sci Med. 2014;116:64-72.

11- Khanna D, Tsevat J. Health-related quality of life--an introduction. Am J Manag Care. 2007;13 Suppl 9:S218-23. 12- Yaffe K, Hoang TD, Byers AL, Barnes DE, Friedl KE. Lifestyle and health-related risk factors and risk of cognitive aging among older veterans. Alzheimer's Dement.10(3 Suppl):S111-21.

13- Litwack SD, Mitchell KS, Sloan DM, Reardon AF, Miller

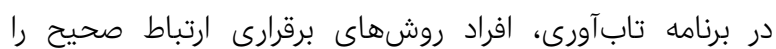

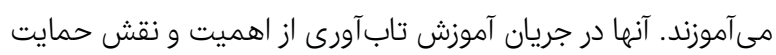

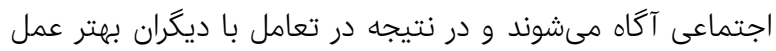

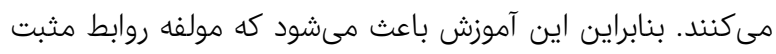

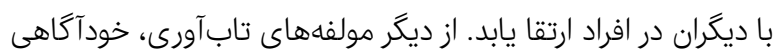

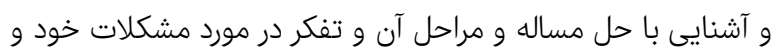

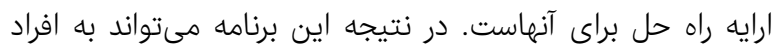

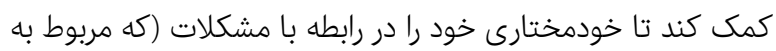

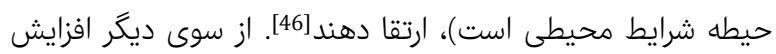

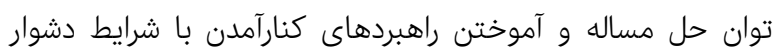

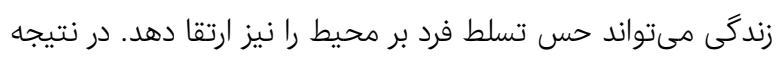

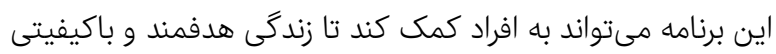

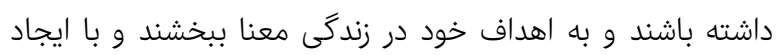

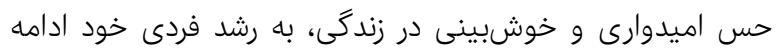
دهند [45, 47.

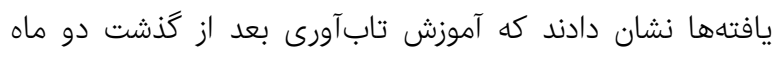

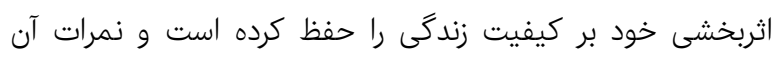

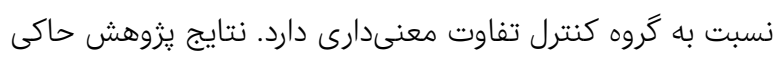

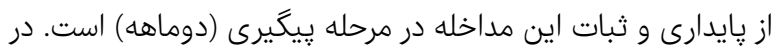

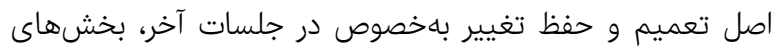

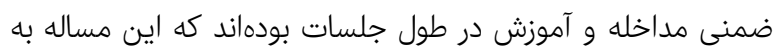

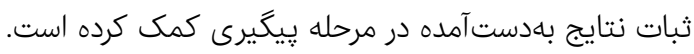

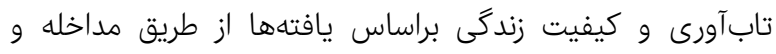

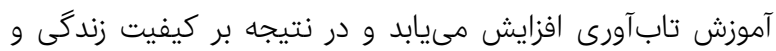

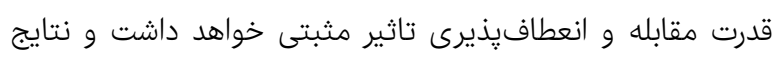

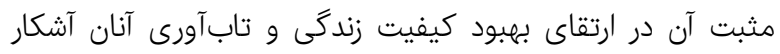

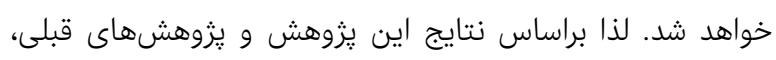

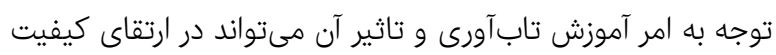

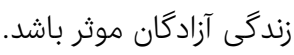

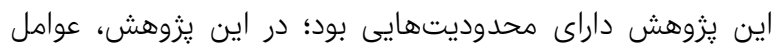

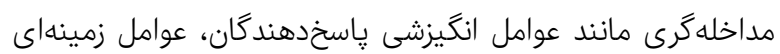

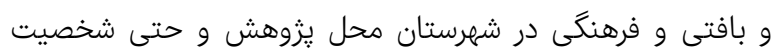

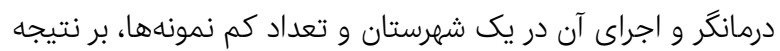
يزوهش تاثيركذار بوده است.

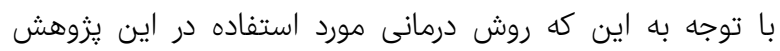

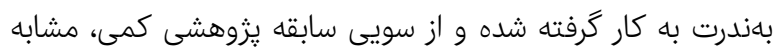

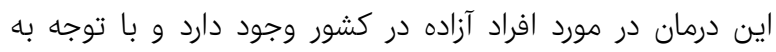

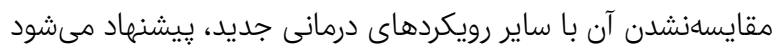

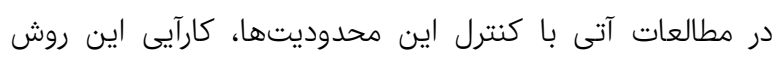

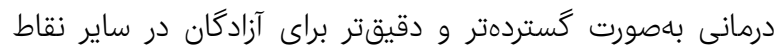
كشور مورد بررسى قرار كيرد.

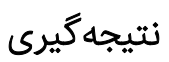
برنامه آموزش تابهيرى تورى مىتواند بر ارتقاى كيفيت زندگى و 
اثربخشى آموزش تابآورى بر بهبود كيفيت زندگى و تابآورى آزادگان و

mental health and quality of life through a resilient education program for mothers of children with learning disorders. Educ Cult J Women Fam. 2014;8(26):39-64. [Persian]

32- Kaveh M, Alizadeh H, Delavar A, Borjali A. Development of a resilience Fostering program against stress and its impact on quality of life components in parents of children with mild intellectual disability. J Except Child. 2011;11(2):119-40. [Persian]

33- Pietrzak RH, Southwick SM. Psychological resilience in OEF-OIF Veterans: Application of a novel classification approach and examination of demographic and psychosocial correlates. J Affect Disord. 2011;133(3):5608.

34- Green KT, Calhoun PS, Dennis MF, Beckham JC. Exploration of the resilience construct in posttraumatic stress disorder severity and functional correlates in military combat veterans who have served since September 11, 2001. J Clin Psychiatry. 2010;71(7):82330.

35- Connor KM, Davidson JR. Development of a new resilience scale: the Connor-Davidson Resilience Scale (CD-RISC). Depress Anxiety. 2003;18(2):76-82.

36- Hagh Ranjbar F, Kakavand A, Borjali A, Bermas H. Resilience and quality of mothers with mentally retarded children. Health Psychol. 2011;1(1):177-87. [Persian] 37- Skevington SM, Lotfy M, O'Connell KA. The World Health Organization's WHOQOL-BREF quality of life assessment: Psychometric properties and results of the international field trial. A report from the WHOQOL group. Qual Life Res. 2004;13(2):299-310.

38- Group W. Development of the world Health organization WHOQOL-BREF quality of life assessment. Psychol Med. 1998;28(3):551-8.

39- Nejat S, Montazeri A, Holakouei Naeini K, Mohammad K, Majdzadeh SR. The World Health organization quality of Life (WHOQOL-BREF) questionnaire: translation and validation study of the Iranian version. J Sch Public Health Instit Public Health Res. 2006;4(4):1-12. [Persian]

40- Benzies K, Mychasiuk R. Fostering family resiliency: a revirw of the key protective factors. Child Fam Soc Work. 2009;14(1):103-14.

41- Resnick B, Gwyther LP, Roberto KA, editors. Resilience in aging. New York: Springer; 2011.

42- Ghasem M, Hosseinchari M. Psychological resilience and Intrinsic - extrinsic motivation: the mediating role of self-efficacy. Deve Psychol: Iran Psychol. 2012;9(33):6171. [Persian]

43- Masten AS. Ordinary magic: resilience processes in development. Am Psychol. 2001;56(3):227-38.

44- Dyess SM, Prestia AS, Smit MC. Support for caring and resiliency among successful nurse leaders. Nurs Adm Q. 2015;39(2):104-16.

45- Seidmahmoodi J, Rahimi C, Mohammadi N. Resiliency and religious orientation factors contributing to posttraumatic growth in Iranian subjects. Iran J Psychiatry. 2011;6(4):145-50.

46- Raoothman B, Kirsten DK, Wissing MP. Gender differences in aspects of psychological well-being. South Afr J Psychol. 2003;33(4):212-8.

47- Mikaeili N, Ganj M, Talebi Jooybari M. A comparison of resiliency, marital satisfaction and mental health in parents of children with learning disabilities and normal children. J Learn Disabil. 2012;2(1):120-37. [Persian]
MW. Eating disorder symptoms and comorbid psychopathology among male and female veterans. Gen Hosp Psychiat. 2014;36(4):406-10.

14- Serowik KL, Ablondi K, Black AC, Rosen MI. Developing a benefits counseling website for Veterans using Motivational Interviewing techniques. Comput Human Behav. 2014;37:26-30.

15- Hoerster KD, Jakupcak M, McFall M, Unützer J, Nelson KM. Mental health and somatic symptom severity are associated with reduced physical activity among US Iraq and Afghanistan veterans. Prev Med. 2012;55(5):450-2. 16- Nejati V, Ahmadi K. Evaluation of epidemiology of chronic disease in Iranian psychiatric veterans. Iran J War Public Health. 2010;2(4):8-12. [Persian]

17- Greeff AP, Loubser K. Spirituality as a resiliency quality in Xhosa-speaking families in South Africa. J Relig Health. 2008;47(3):288-301.

18- Loh JM, Schutte NS, Thorsteinsson EB. Be happy: The role of resilience between characteristic affect and symptoms of depression. J Happiness Stud. 2014;15(5):1125-38.

19- MacLeod S, Musich S, Hawkins K, Alsgaard K, Wicker ER. The impact of resilience among older adults. Geriatr Nurs. 2016;37(4):266-72.

20- Wu G, Feder A, Cohen H, Kim JJ, Calderon S, Charney DS, et al. Understanding resilience. Front Behav Neurosci. 2013;7:10.

21- Richardson GE. The metatheory of resilience and resiliency. J Clinic Psychol. 2002;58(3):307-22.

22- Cohen M, Baziliansky S, Beny A. The association of resilience and age in individuals with colorectal cancer: an exploratory cross-sectional study. J Geriatr Oncol. 2014;5(1):33-9.

23- Stewart DE, Yuen T. A systematic review of resilience in the physically ill. Psychosomatics. 2011;52(3):199-209. 24- Nawaz A, Malik JA, Batool A. Relationship between resilience and quality of life in diabetics. J Coll Physicians Surg Pak. 2014;24(9):670-5.

25- Yazdi-Ravandi S, Taslimi Z, Saberi H, Shams J, Osanlo $\mathrm{S}$, Nori G, et al. The role of resilience and age on quality of life in patients with pain disorders. Basic Clin Neurosci. 2013;4(1):24-30.

26- Mosqueiro BP, da Rocha NS, Fleck MPA. Intrinsic religiosity, resilience, quality of life, and suicide risk in depressed inpatients. J Affect Disord. 2015;179:128-33.

27- Li MY, Yang YL, Liu L, Wang L. Effects of social support, hope and resilience on quality of life among Chinese bladder cancer patients: a cross-sectional study. Health Qual Life Outcomes. 2016;14(1):73-82.

28- Fauci AJ, Bonciani M, Guerra R. Quality of life, vulnerability and resilience: A qualitative study of the tsunami impact on the affected population of Sri Lanka. Ann Ist Super Sanita. 2012;48(2):177-88.

29- Aidelkhani S, Heydari H. Measuring the effectiveness of resilience training on the mental health and quality of life of the handicapped veterans' wives. J Milit Psychol. 2016;7(27):67-80. [Persian]

30- Ashtari N, Pourebrahim T, Khodabakhshi Koolaei A, Khoshkonesh A, Khatiban M. The efficacy of group awareness training of premenstrual syndrome on psychological resilience and quality of life in female high school students. Sci J Hamadan Nurs Midwifery Fac. 2015;23(1):63-73. [Persian]

31- Momeni K, Ebrahimi P, Hosseinian S. Improving 